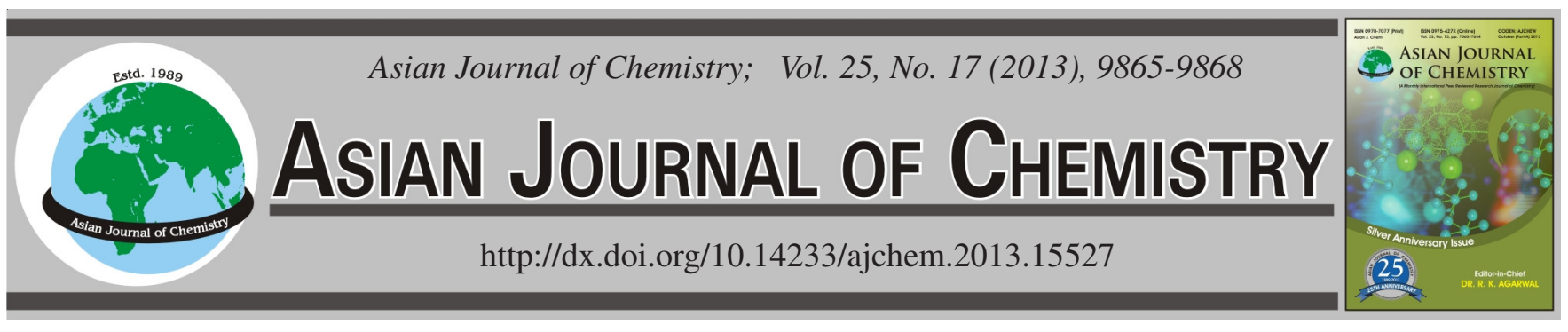

\title{
Thermodynamics Properties of Micellization of Organosilicone Modified Gluconamide-Type Surfactant
}

\author{
LEI TAO
}

School of Environment and Safety, Taiyuan University of Science and Technology, Taiyuan 030006, Shanxi Province, P.R. China

Corresponding author: E-mail: leitao030006@126.com

Thermodynamic properties of micellization of N-3-propylmethyltrisiloxane-N-glucosylamine in water over a temperature range of 298 to $313 \mathrm{~K}$ been studied with surface tension method. On the basis of these results, the thermodynamic parameters i.e., Gibbs energy $\left(\Delta \mathrm{G}_{\mathrm{m}}^{\mathrm{o}}\right)$, enthalpy $\left(\Delta \mathrm{S}_{\mathrm{m}}^{\circ}\right)$ and entropy $\left(\Delta \mathrm{H}_{\mathrm{m}}^{\mathrm{o}}\right)$ of micellization have been evaluated.

Key Words: Thermodynamics Properties, Micellization, Organosilicone, Gluconamide, Surfactant.

\section{INTRODUCTION}

With an increasing environmental concern, sugar-based surfactant with hydrophilic sugar groups has attracted the attention of researchers worldwide, because sugar-based surfactants have good excellent biodegradability, good dermatological compatibility and the absence of toxic effects ${ }^{1}$.

Generally silicone surfactant with hydrophobic siloxane group can produce lower surface tension than hydrocarbon surfactant. Because the flexible siloxane backbone can adopt orientations while it lies flat on the surface of the water, favouring exposing the low surface energy methyl groups substations to the air ${ }^{2,3}$.

These unique properties prompted a lot of researchers to integrate sugar and siloxane's advantage. In spite of a few papers and patents have reported siloxane modified sugar based surfactants $^{4-10}$, relatively little is known about the thermodynamics properties of micellization of this interesting class of compounds. In this work, we reported the thermodynamics properties of micellization of N-3-propylmethyltrisiloxane$\mathrm{N}$-glucosylamine [abbreviated as $\mathrm{Si}(3) \mathrm{N}-\mathrm{GA}$ ] in water over a temperature range of 298 to $313 \mathrm{~K}$

\section{EXPERIMENTAL}

3-Aminopropylmethyldiethoxysilane, hexamethyldisiloxane were purchased from Beijing Chemical Reagents Company and were used without further purification. Double distilled water was used for the analysis and for the measurements of primary properties.
Infrared spectroscopy was performed with a Fourier Transform Infrared Spectrometer (Hitachi 270-30). The surfactants were smeared directly onto a $\mathrm{KBr}$ plate. Proton nuclear magnetic resonance $\left({ }^{1} \mathrm{H}\right.$ and ${ }^{13} \mathrm{C}$ NMR) spectroscopy was recorded in $\mathrm{CDCl}_{3}$ with aVarian INOVA-400 $\mathrm{MHz}$ spectrometer. Since TMS cannot easily be used as internal standard because of the overlapping with other methyl signals, we used the residual protons of the solvent at $7.26 \mathrm{ppm}$ as the reference.

Measurement of surface tension: Equilibrium surface tension values of the surfactants in aqueous solution were obtained by the Wilhelmy plate method using a model K12 Krüss tensiometer (Hamburg, Germany). Prior to measurement, the surface tension of the distilled, deionized water was measured. These values were in the range of $72.3 \pm 0.3 \mathrm{mN} / \mathrm{m}$. Surfactant solutions were then prepared with this water and the samples were left for $15 \mathrm{~min}$ prior to surface tension measurement.

Synthesis of 3-aminopropyltrisiloxane: The mixture of 3-aminopropylmethyldiethoxysilane $(28.79 \mathrm{~g}, 0.15 \mathrm{~mol})$, hexamethyldisiloxane $(121.89 \mathrm{~g}, 0.75 \mathrm{~mol})$ and tetramethyl ammonium hydroxide $(0.735 \mathrm{~g}, 0.008 \mathrm{~mol})$ was heated for $2 \mathrm{~h}$ at $90{ }^{\circ} \mathrm{C}$ under nitrogen atmosphere, with stirring. The resulting quaternary ammonium hydroxide was then deactivated by heating for $0.5 \mathrm{~h}$ at $130^{\circ} \mathrm{C}$ and the excess hexamethyldisiloxane was simultaneously distilled from the mixture. The liquid product was purified by fractional distillation. Colourless liquid, $22.2 \mathrm{~g}$ (yield: $52.9 \%$ ), boiling point (b.p.) $85^{\circ} \mathrm{C} / 1.5$ mmHg. IR $\left(\mathrm{KBr}, \mathrm{v}_{\max }, \mathrm{cm}^{-1}\right): 3300(\mathrm{O}-\mathrm{H}), 1260\left(\mathrm{Si}_{-} \mathrm{Me}_{3}\right), 1100$ ( $\mathrm{Si}-\mathrm{O}-\mathrm{Si}), 840\left(\mathrm{Si}-\mathrm{Me}_{3}\right), 760\left(\mathrm{Si}-\mathrm{Me}_{3}\right) .{ }^{1} \mathrm{H} \mathrm{NMR}\left(\mathrm{CDCl}_{3}, \mathrm{ppm}\right)$

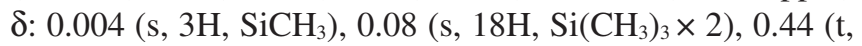


$\left.2 \mathrm{H}, J=8.4 \mathrm{~Hz}, \mathrm{SiCH}_{2}\right), 1.40-1.44\left(\mathrm{~m}, 2 \mathrm{H}, \mathrm{CH}_{2} \mathrm{CH}_{2} \mathrm{NH}_{2}\right), 1.5$ (s, $2 \mathrm{H}, \mathrm{NH}_{2}$ ), 2.64 (t, $2 \mathrm{H}, J=7.2 \mathrm{~Hz}, \mathrm{CH}_{2} \mathrm{~N}$ ). Elemental analysis $(\%)$ calcd for $\mathrm{C}_{10} \mathrm{H}_{29} \mathrm{NO}_{2} \mathrm{Si}_{3}: \mathrm{C}, 49.26 ; \mathrm{H}, 10.45 ; \mathrm{N}, 5.01$. Found: C, 49.40; H, 10.28; N, 5.09.

Synthesis of N-3-propylmethyltrisiloxane-N-glucosylamine: 3-aminopropyltrisiloxane (1.8 g, $0.0064 \mathrm{~mol})$, was dissolved in $50 \mathrm{~mL}$ of dry methanol. D-(+)-gluconic acid $\delta$-lactone $(1.147 \mathrm{~g}, 0.0064 \mathrm{~mol})$ was added and the mixture was heated to reflux temperature for $6 \mathrm{~h}$. After cooling to room temperature and evaporation of the solvent the solid residue was gently crushed, washed several times with hexane at $30{ }^{\circ} \mathrm{C}$ and dried under reduced pressure to a constant mass. The yield was white powder, $2.369 \mathrm{~g}$.

IR $\left(\mathrm{KBr}, \mathrm{cm}^{-1}\right): 3300 \mathrm{v}(\mathrm{O}-\mathrm{H}), 1646[\mathrm{v}(\mathrm{C}=\mathrm{O})$ in amide], $1547\left[\delta(\mathrm{N}-\mathrm{H})\right.$ in amide], $1467 \mathrm{~cm}^{-1}\left[\mathrm{v}(\mathrm{C}-\mathrm{H})\right.$ in $\left.-\mathrm{CH}_{2}-\right], 1260$ $v\left(\mathrm{Si}-\mathrm{Me}_{3}\right), 1146-1035 \mathrm{~cm}^{-1}[\mathrm{v}(\mathrm{C}-\mathrm{O}), \delta(\mathrm{O}-\mathrm{H})$ and $v(\mathrm{Si}-\mathrm{O}-\mathrm{Si})]$, $840 v\left(\mathrm{Si}_{-} \mathrm{Me}_{3}\right), 760 v\left(\mathrm{Si}-\mathrm{Me}_{3}\right) .{ }^{1} \mathrm{H} \mathrm{NMR}\left(\mathrm{CDCl}_{3}, \mathrm{ppm}\right) \delta: 0.03$ $\left(\mathrm{s}, 3 \mathrm{H}, \mathrm{SiCH}_{3}\right), 0.10$ (s, 18H, $\left.\mathrm{Si}\left(\mathrm{CH}_{3}\right)_{3} \cdot 2\right), 0.45$ (t, $2 \mathrm{H}, J=8.4$ $\mathrm{Hz}, \mathrm{SiCH}_{2}$ ), 1.54 (s, $2 \mathrm{H}, \mathrm{SiCH}_{2} \mathrm{CH}_{2} \mathrm{CH}_{2}$ ), 3.26 and 3.13 (d, $\left.2 \mathrm{H}, \mathrm{CH}_{2} \mathrm{~N}\right), 4.30$ (s, 1H, H2), 4.13 (s, 1H, H3), 3.74 (m, 4H, $\left.\mathrm{H} 4+\mathrm{H} 5+\mathrm{H} 6+\mathrm{H}^{\prime}\right)$. Elemental analysis (\%) calcd for $\mathrm{C}_{16} \mathrm{H}_{39} \mathrm{NO}_{8} \mathrm{Si}_{3}$ : C, 41.98; H, 8.59; N, 3.06. Found: C, 42.10; H, $8.40 ; \mathrm{N}, 3.19$.

\section{RESULTS AND DISCUSSION}

The glucosamide-based trisiloxane surfactant was prepared by the two step process described in Scheme-I.

Amine intermediate was synthesized by the base-catalyzed reaction of a silane monomer 3-aminopropylmethyl diethoxysilane and hexamethyldisiloxane. The complete substitution $\mathrm{OCH}_{3}$ by $\mathrm{Me}_{3} \mathrm{SiO}$ was checked by ${ }^{1} \mathrm{H}$ NMR spectroscopy, following the disappearance of $\mathrm{OCH}_{3}$ absorption peak at 3.48 ppm as well as the appearance of $\mathrm{Si}-\mathrm{Me}_{3}$ characteristic absorption at $0.10 \mathrm{ppm}$. Similarly in IR spectrum, the appearance of $\mathrm{Si}-\mathrm{CH}_{3}$ deformation absorption at $1260 \mathrm{~cm}^{-1}$ and $\mathrm{Si}-\mathrm{Me}_{3}$ characteristic absorption at 840 and $760 \mathrm{~cm}^{-1}$ (Fig. 1), respectively also support the formation of the 3-aminopropylmethyltrisiloxane.

D-(+)-Gluconic acid $\delta$-lactone was ring-opened by nucleophilic attack of the primary amine. The amidation of the

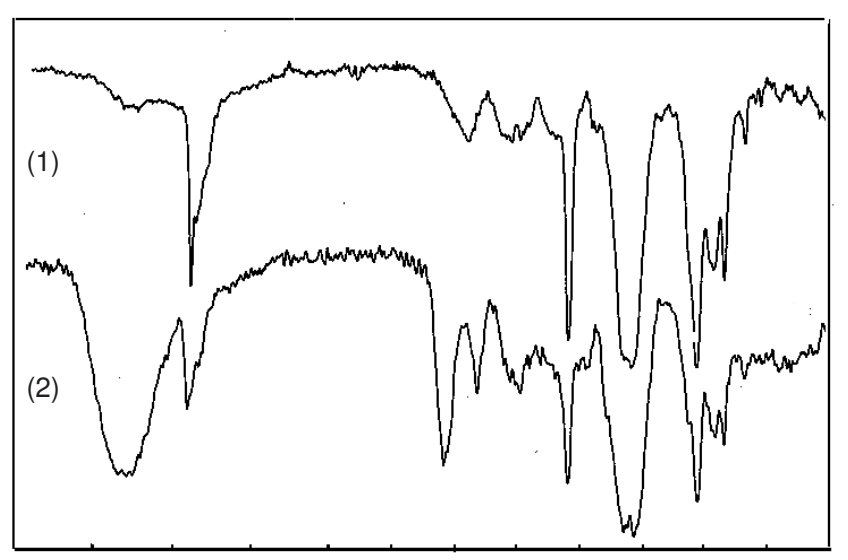

4000350030002500200018001600140012001000800600400

Fig. 1. FT-IR spectra of (1) 3-aminopropyltrisiloxane, (2) N-3propylmethyltrisiloxane-N-glucosylamine

primary amine proceeded in the presence of the methanol at reflux temperature. The structure of amide was confirmed by proton nuclear magnetic spectroscopy. The protons of the carbon adjacent to the free amine $\left(\mathrm{CH}_{2}-\mathrm{NH}_{2}\right)$ are seen at 2.64 ppm, while the same protons after amide formation through coupling with the lactone $\left(\mathrm{CH}_{2}-\mathrm{NHCO}\right)$ shift to 3.26 and 3.13 ppm. This shift is observed in the spectrum (Fig. 2), verifying the absence of free amino groups and indicating pure glucosylamine surfactants up to the detection limit of the analysis. In amide the hydrogen of $\mathrm{C} 1$ and $\mathrm{C} 2$ are adjacent to the carbonyl function and shows a low-field shift, $4.30 \mathrm{ppm}$ and 4.13 ppm respectively. The signals of the hydrogen atoms in $\mathrm{C} 3-\mathrm{C} 6$ were assigned according to the literature. All other hydrogen atoms have observed in their normal positions. In IR spectrum strong absorption at 1646 and $1547 \mathrm{~cm}^{-1}$ indicate the formation of amide bonds.

Thermodynamic properties of micellization $\mathrm{Si}(3) \mathrm{N}$ GA: The equilibrium surface tensions of dilute aqueous solutions of N-3-propylmethyltrisiloxane-N-glucosylamine were measured (Fig. 3). The surface tension of $\mathrm{Si}(3) \mathrm{N}-\mathrm{GA}$ aqueous solution decreased with increasing the surfactant concentration until the $\mathrm{CMC}$ above the $\mathrm{CMC}$, the surface tension became steady. As shown in Fig. 3, Si(3)N-GA is highly

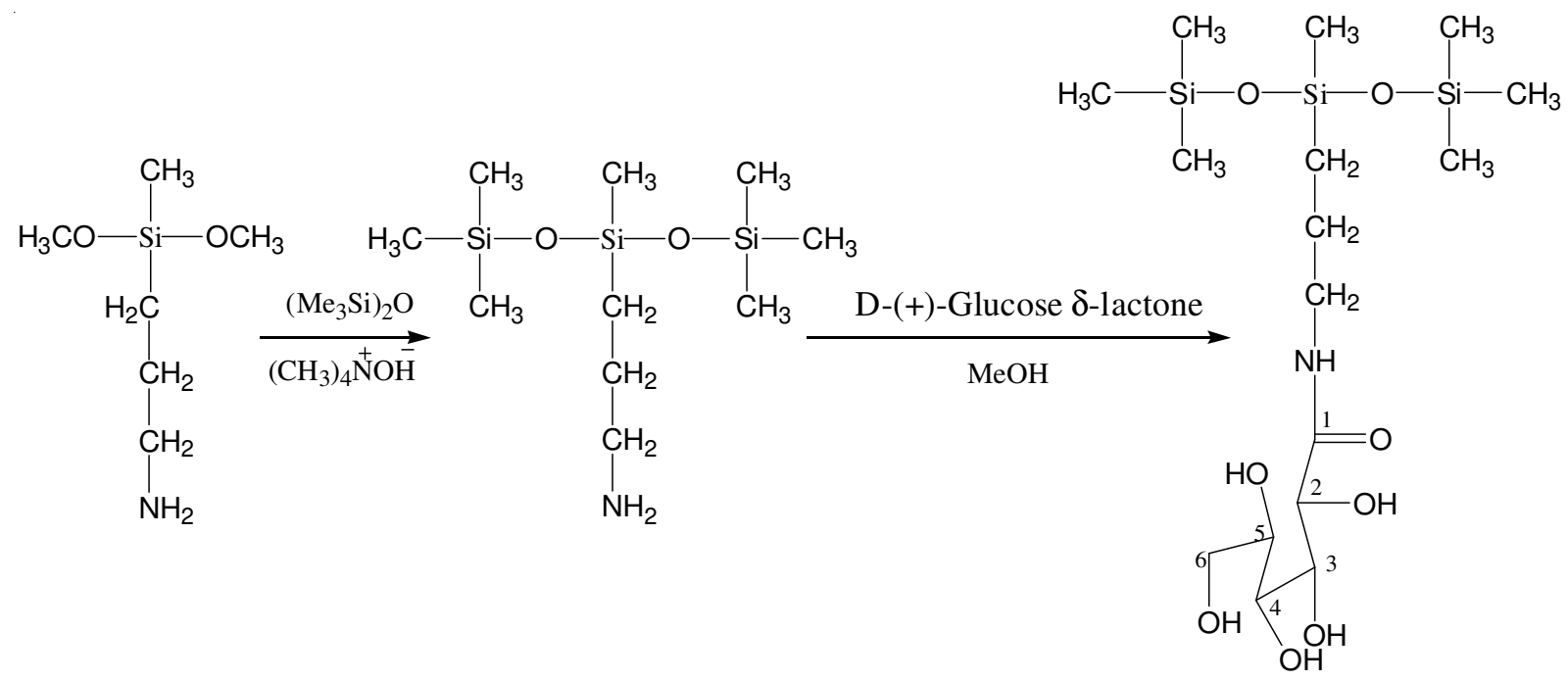

Scheme-I: Synthesis of N-3-propylmethyltrisiloxane-N-glucosylamine 


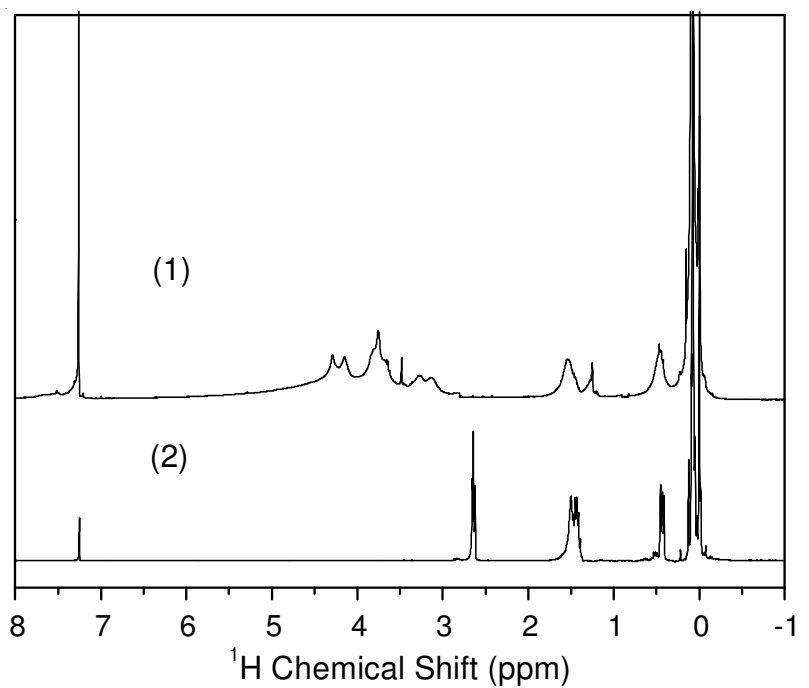

Fig. 2. $400 \mathrm{MHz}{ }^{1} \mathrm{H}$ NMR spectra in $\mathrm{CDCl}_{3}$, (1) N-3-propylmethyl trisiloxane- $\mathrm{N}$-glucosylamine, (2) 3-aminopropyltrisiloxane

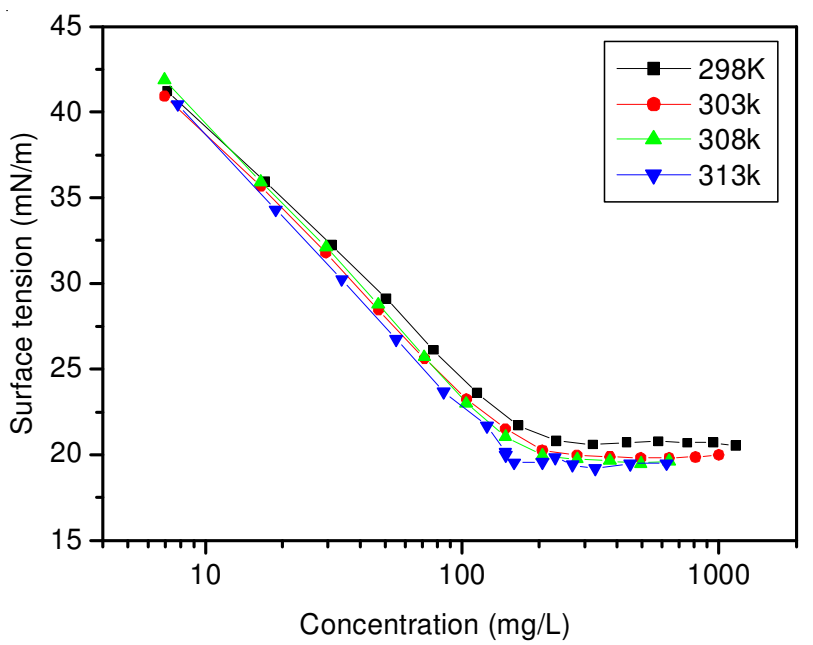

Fig. 3. Plots of equilibrium surface tensions of aqueous solutions of the new trisiloxanes versus logarithm of molar concentration at different temperature

effective aqueous surfactant reducing the surface tension of water to approximate $21-22 \mathrm{mN} / \mathrm{m}$. These values of $\gamma_{\text {СMC }}$ are significantly lower than those reported for hydrocarbon surfactants ${ }^{11}$ and are comparable to those reported for other low molecular weight silicone surfactants ${ }^{12}$.

By applying the approximate form of the Gibbs adsorption isotherm equations (eqn. 1 and 2) to the steeply descending, linear portion of the surface tension versus log concentration plots (Fig. 2), the saturation adsorption values, $\Gamma_{\max }$, at the air/ water interface and the minimum area per surfactant molecule, $\mathrm{A}_{\mathrm{s}}^{\mathrm{m}}$, at the air/water interface were obtained for each of the novel trisiloxane surfactants. The adsorption data and $\mathrm{A}_{\mathrm{s}}^{\mathrm{m}}$ are summarized in Table- 1 .

$$
\begin{gathered}
\Gamma_{\max }=-\frac{1}{2.303 R T}\left(\frac{\partial \gamma}{\partial \log \mathrm{c}}\right)_{\mathrm{T}} \\
\mathrm{A}_{\mathrm{m}}^{\mathrm{s}}=\frac{10^{16}}{\mathrm{~N}_{\mathrm{A}} \Gamma_{\max }} \\
\Delta \mathrm{G}_{\mathrm{mic}}^{0}=\mathrm{RT} \ln \left(\frac{\mathrm{CMC}}{55.5}\right) \\
\Delta \mathrm{G}_{\mathrm{ads}}^{0}=\mathrm{RT} \operatorname{In}\left(\frac{\mathrm{C}_{\pi}}{55.5}\right)-6.022 \pi \mathrm{A}_{\mathrm{m}}^{\mathrm{s}}
\end{gathered}
$$

where $\mathrm{R}=8.3144 \mathrm{~J} / \mathrm{mol} \mathrm{K}, \mathrm{N}_{\mathrm{A}}$ is Avogadro's number and $\mathrm{A}^{\mathrm{m}}{ }_{\mathrm{s}}$ in $\AA^{2}$ per molecule. $\pi\left(=\gamma_{0}-\gamma\right)$ the surface pressure in the region of surface saturation and $\mathrm{Cp}$ the molar concentration of surfactant in the aqueous phase at a surface pressure $\pi$ (in $\mathrm{mN} / \mathrm{m}$ ).

The enthalpies of micellization were calculated using eqn. 5:

$$
\Delta \mathrm{H}_{\mathrm{m}}^{0}=\mathrm{RT}^{2} \operatorname{In}\left(\frac{\partial \mathrm{In} \mathrm{CMC}}{\partial \mathrm{T}}\right)
$$

Therefore, if the dependence of the CMC values on temperature is known, a plot of $\ln \mathrm{CMC} v s$. temperature can be constructed. The slope can then be found at each temperature.

These plots were found to be best fit with a second-order polynomial $\left(r^{2}=0.95\right)$. The plot is presented in Fig. 4 . The entropies of micellization were then calculated from eqn. 6

$$
\Delta \mathrm{S}_{\mathrm{m}}^{0}=\frac{\Delta \mathrm{H}_{\mathrm{m}}^{0}-\Delta \mathrm{G}_{\mathrm{m}}^{0}}{\mathrm{~T}}
$$

Thermodynamics of micellization were calculated for $\mathrm{Si}(3)$ N-GA in aqueous solution. The parameter values obtained

\begin{tabular}{|c|c|c|c|c|c|}
\hline Temperature & $\gamma_{\text {cac }}(\mathrm{mN} / \mathrm{m})$ & $\mathrm{CAC}(\mathrm{mol} / \mathrm{L})$ & $A_{\mathrm{s}}^{\mathrm{m}}\left(\AA^{2} /\right.$ molecule $)$ & $\Delta \mathrm{G}_{\text {mic }}^{0}(\mathrm{KJ} / \mathrm{mol})$ & $\Gamma_{\max }\left(\mathrm{mol} / \mathrm{m}^{2}\right)$ \\
\hline 298 & 20.54 & $4.13 \times 10^{-4}$ & 65.1 & -29.25 & $2.55 \times 10^{-10}$ \\
\hline 303 & 19.70 & $4.06 \times 10^{-4}$ & 64.3 & -29.78 & $2.59 \times 10^{-10}$ \\
\hline 308 & 19.61 & $3.66 \times 10^{-4}$ & 61.5 & -30.04 & $2.70 \times 10^{-10}$ \\
\hline 313 & 19.54 & $3.47 \times 10^{-4}$ & 60.6 & -30.18 & $2.74 \times 10^{-10}$ \\
\hline
\end{tabular}
are given in Table- 2 .

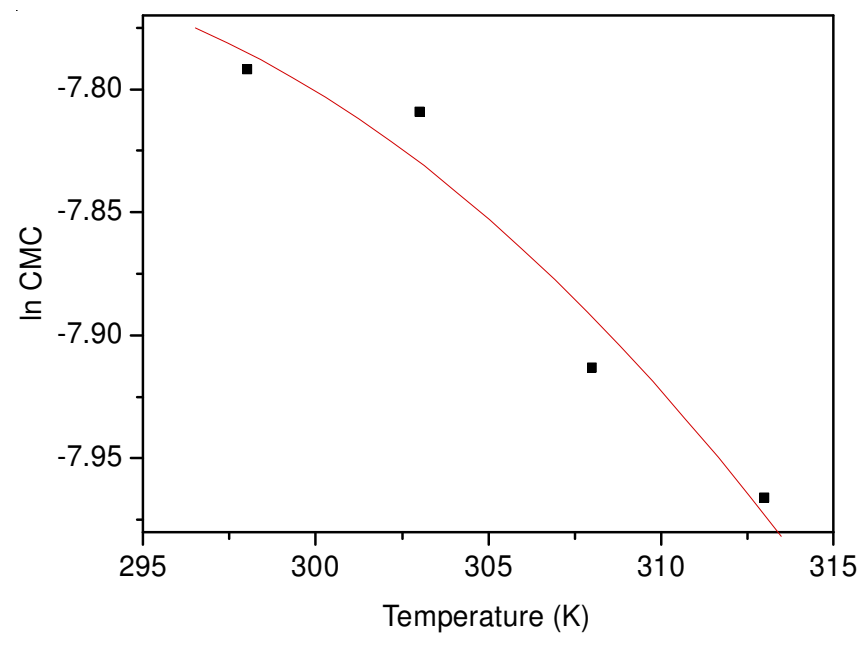

Fig. 4. Variation of $\ln \mathrm{CMC}$ with temperature

TABLE-1 AQUEOUS SURFACE ACTIVITY OF THE NEW TRISILOXANES AT DIFFERENT TEMPERATURE 
TABLE-2

THERMODYNAMIC PARAMETERS OF Si(3)N-GA

\begin{tabular}{ccccc}
\hline Temperature $(\mathrm{K})$ & $\Delta \mathrm{H}_{\mathrm{m}}^{\mathrm{o}}(\mathrm{KJ} / \mathrm{mol})$ & $\Delta \mathrm{S}_{\mathrm{m}}^{\circ}\left(\mathrm{J} \cdot \mathrm{K}^{-1} / \mathrm{mol}\right)$ & $-\Delta \mathrm{G}_{\mathrm{m}}^{\circ}(\mathrm{KJ} / \mathrm{mol})$ & $\mathrm{T} \cdot \Delta S_{\mathrm{m}}^{\circ}(\mathrm{KJ} / \mathrm{mol})$ \\
\hline 298 & 2.510 & 106.0 & 29.247 & 31.588 \\
303 & 9.236 & 128.0 & 29.781 & 38.784 \\
308 & 12.38 & 137.7 & 30.042 & 42.412 \\
313 & 8.634 & 124.0 & 30.177 & 38.812 \\
\hline
\end{tabular}

The data available indicate that the negative values of $\Delta \mathrm{G}_{\mathrm{m}}^{\mathrm{o}}$ are mainly due to the large positive values of $\Delta \mathrm{S}_{\mathrm{m}}^{\mathrm{o}} . \Delta \mathrm{H}_{\mathrm{m}}^{\mathrm{o}}$ is positive and is much smaller than the value of $\mathrm{T} \Delta \mathrm{S}_{\mathrm{m}}^{\circ}$. Therefore, the micellization process is governed primarily by the entropy gain associated with it and the driving force for the process is the tendency of the hydrophobic group of the surfactant to transfer from the solvent environment to the interior of the micelle.

This large entropy increase on micellization in aqueous medium has been explained in two ways: (1) structuring of the water molecules surrounding the siloxane chains in aqueous medium, resulting in an increase in the entropy of the system when the siloxane chains are removed from the aqueous medium to the interior of the micelle-hydrophobic bonding; (2) increased freedom of the hydrophobic chain in the nonpolar interior of the micelle compared to the aqueous environment

An increase in temperature seems to cause both $\Delta \mathrm{H}_{\mathrm{m}}^{\mathrm{o}}$ and $\Delta \mathrm{S}_{\mathrm{m}}^{\mathrm{o}}$ to become more positive, presumably because both the amount of water structured by the hydrophobic chain and the amount of water bound by the hydrophilic sugar group in the nonmicellar species increase with increase in temperature, resulting in a increase in $\Delta \mathrm{H}^{\circ}$ m and $\Delta \mathrm{S}_{\mathrm{m}}^{\mathrm{o}}$, respectively. Since these two parameters have opposite effects on $\Delta \mathrm{G}_{\mathrm{m}}^{\mathrm{o}}$, it may become more negative or less negative with temperature change, depending on the relative magnitude of the changes in $\Delta \mathrm{H}^{\circ}{ }_{\mathrm{m}}$ and $\Delta \mathrm{S}_{\mathrm{m}}^{\mathrm{o}}$. From the above data, $\Delta \mathrm{G}^{\circ}{ }_{\mathrm{m}}$ appears to become more negative with increase in temperature.

The values of $\Delta \mathrm{H}_{\mathrm{m}}^{\mathrm{o}}$ in Table-2 indicate that the micellization processes in water are exothermic. The variation of $\Delta \mathrm{H}_{\mathrm{m}}^{\mathrm{o}}$ with temperature is due to a change in the hydration of the head groups during micellization. The micellization of surfactants in water may be understood on the basis of water structure and hydrophobic interaction. Generally, the structure of liquid water is considered in terms of a 3-dimensional hydrogen bonded "flickering cluster" which retains much of the ordered structure of ice. The entropy change is positive in all cases. However it decreases with increasing temperature. The positive values of standard entropy of micelle formation $\Delta \mathrm{S}_{\mathrm{m}}^{\circ}$ are due to the melting of "flickering cluster" around hydrocarbon tails of the surfactant monomer and the increased randomness of the hydrocarbon chains in the micelle core. Amphiphilic monomers with a long hydrocarbon chain increase the orderliness of water by formation of a "Frank-Evan iceberg" around the hydrocarbon chain. This results in a decrease in the entropy of the system. The enthalpy entropy compensation plots for the $\mathrm{Si}(3) \mathrm{N}-\mathrm{GA}$ in all the solvent mixtures showed a good correlation between the thermodynamic parameters. The plots indicate that the change in $\Delta \mathrm{H}^{\circ}{ }_{\mathrm{m}}$ is effectively balanced by a corresponding change in $\Delta \mathrm{S}_{\mathrm{m}}^{\mathrm{o}}$.

Free energy and enthalpy were negative whereas entropy was positive. The minimal effect of temperature on the thermodynamic parameters indicates that the process of micellization was spontaneous in nature.

\section{Conclusion}

By using Wilhelmy plate method, the surface tension of Si(3)N-GA at different temperatures (298-313 K). The results show that with the increase of temperature, the critical micelle concentration (CMC) of $\mathrm{Si}(3) \mathrm{N}-\mathrm{GA}$ slightly decreases, but the maximum surface excess concentration at the air/ water interface increases. The micellization free energies $\left(\Delta \mathrm{G}^{\circ}{ }_{\text {mic }}\right.$ ) are in the range -29.247--30.177 $\mathrm{kJ} \mathrm{mol}^{-1}$ in the studied ranges of temperature. The process of micellization of $\mathrm{Si}(3) \mathrm{N}-$ GA in aqueous solution is mainly driven by the entropy.

\section{ACKNOWLEDGEMENTS}

The authors acknowledged the financial support of Youth Fund of Taiyuan University of Science and Technology (No. 20113009) and the National Natural Science Foundation of China.

\section{REFERENCES}

1. M. Hato, H. Minamikawa and T. Kato, Surfact. Sci. Ser, 143, 361 (2009).

2. R.M. Hill, Surfact. Sci. Ser., 86, 1 (1999).

3. G.Y. Wang, Z.P. Du, W. Zhang and Q.Y. Cao, Tenside Surfact. Detergents, 46, 214 (2009).

4. R. Wagner, Y. Wu, L. Richter, J. Reiners, J. Weissmuller and A. De Montigny, Appl. Organomet. Chem., 13, 21 (1999).

5. K. Loos, G. Jonas and R. Stadler, Macromol. Chem. Phys., 202, 3210 (2001).

6. F. Han and G. Zhang, Tenside, Surfact. Deterg., 40, 332 (2003).

7. F. Han and G. Zhang, Colloids Surf. A, 237, 79 (2004).

8. G.Y. Wang, W.S. Qu, Z.P. Du, Q.Y. Cao and Q.X. Li, J. Phys. Chem. B, 115, 3811 (2011).

9. G. Wang, Z. Du, Q. Li and W. Zhang, J. Phys. Chem. B, 114, 6872 (2010).

10. G.Y. Wang, W.S. Qu, Z.P. Du, W.X. Wang and Q.X. Li, J. Phys. Chem. B, 117, 3154 (2013).

11. K. Sakai, S. Umezawa, M. Tamura, Y. Takamatsu, K. Tsuchiya, K. Torigoe, T. Ohkubo, T. Yoshimura, K. Esumi and H. Sakai, J. Colloid Interf. Sci., 318, 440 (2008).

12. S.A. Snow, Langmuir, 9, 424 (1993). 